\title{
Féeries
}

Études sur le conte merveilleuX, XVII $-\mathrm{XIX}{ }^{\mathrm{e}}$ siècle

\section{Mademoiselle Lhéritier, Mademoiselle Bernard, Mademoiselle de La Force, Madame Durand, Madame d'Auneuil, Contes}

Édition critique établie par Raymonde Robert, Paris, Honoré Champion, collection «Bibliothèque des Génies et des Fées, vol. 2 », 2005. 776 p.

Jean Mainil

\section{OpenEdition}

\section{Journals}

Édition électronique

URL : http://journals.openedition.org/feeries/173

DOI : $10.4000 /$ feeries. 173

ISSN : 1957-7753

\section{Éditeur}

UGA Éditions/Université Grenoble Alpes

\section{Édition imprimée}

Date de publication : 1 février 2006

Pagination : 377-378

ISBN : 2-84310-082-8

ISSN : 1766-2842

\section{Référence électronique}

Jean Mainil, « Mademoiselle Lhéritier, Mademoiselle Bernard, Mademoiselle de La Force, Madame

Durand, Madame d'Auneuil, Contes », Féeries [En ligne], 3 | 2006, mis en ligne le 07 février 2007, consulté le 24 septembre 2020. URL : http://journals.openedition.org/feeries/173 ; DOI : https:// doi.org/10.4000/feeries. 173

Ce document a été généré automatiquement le 24 septembre 2020

(c) Féeries 


\section{Mademoiselle Lhéritier, Mademoiselle Bernard, Mademoiselle de La Force, Madame Durand, Madame d'Auneuil, Contes}

Édition critique établie par Raymonde Robert, Paris, Honoré Champion, collection « Bibliothèque des Génies et des Fées, vol. 2 », 2005. 776 p.

Jean Mainil

1 Une brève «Introduction » qui situe de manière succincte la production du « Cercle des conteuses » (p. 7-11) est suivie d'une «Bibliographie générale » sur deux pages et en quatre parties, la première, "Sur l'écriture féminine au xviıe siècle ", une deuxième "Sur les contes de fées au xvire siècle », une troisième, "Sur la littérature populaire » et une quatrième, la liste des "Dictionnaires utilisés ». Cette bibliographie forcément limitée vient en complément de celle qui figure en fin de la réédition du livre de Raymonde Robert (Champion, 2002) (bibliographie par Nadine Jasmin et Claire Debru).

Dans cette édition, l'œuvre de chaque conteuse est introduite par des « Notices » fort utiles, notices biographiques, notices sur chaque texte en particulier et pour terminer, une «Bibliographie » des éditions, du xvire au $\mathrm{xx}^{\mathrm{e}}$ siècle ainsi que de diverses éditions critiques.

Les avantages et intérêts de cette édition sont nombreux. Tout d'abord, R. Robert a choisi quelques textes importants pour l'histoire du conte et pour sa poétique, textes dont certains n'avaient pas été republiés depuis plus de trois siècles. On trouve donc non seulement des contes qui n'étaient plus disponibles depuis longtemps, écrits par des conteuses moins connues que Marie-Jeanne Lhéritier. Et on trouve aussi, de cette conteuse plus connue, des nouvelles qui contiennent des contes et permettent donc de mieux comprendre la signification de ceux-ci par leur lieu d'énonciation. C'est le cas de Ricdin Ricdon et de La Robe de sincérité insérés dans La Tour ténébreuse et les jours lumineux (1705), mais aussi de la « Lettre à madame $\mathrm{D} \mathrm{G}^{* * *}$ » insérée à l'origine dans les CEuvres meslées (1695) et ensuite dans les Bigarrures ingénieuses. Ce document long de sept pages 
est l'un des textes-clefs sur le conte : il est au conte de fées ce que Sur l'origine des romans de Huet est au roman. On aurait aimé (mais il s'agit sans doute d'une considération éditoriale de longueur) que le même principe d'une meilleure compréhension du conte dans son contexte narratif s'applique aussi aux deux contes de Catherine Bernard, Le Prince Rosier et Riquet à la houppe qui ont été soustraits à leur contexte originel, la nouvelle Inès de Cordoue.

4 La réédition de contes et de nouvelles est accompagnée de fort utiles «Résumés des contes » qui permettent de trouver avec rapidité une référence oubliée ou confondue avec une autre, résumés dont la rédaction tient parfois de la gageure. Un «Index des personnages des contes " en dernière partie permet aux lecteurs de retrouver avec facilité les contes où figurent certains personnages. Dans un univers où des Nabote cohabitent avec des Laideronnette, des fées Babillarde avec une autre Badine ou une autre Brillante, il est facile de s'égarer. L'index facilite l'identification rapide des contes où apparaissent fées, héros et héroïnes, Constant, Curieux, Désirs, Faveur, Finette (plus connue) ou encore Finfin (moins connu).

5 On ne peut que se réjouir de la remise en circulation d'un corpus de contes de fées de l'Âge classique par «ces femmes qui écrivent toutes en marge de la littérature savante ou de la grande poésie » (Sermain, Le Conte de fées, 31) et que la tradition et l'histoire littéraires ont longtemps oubliées ou malmenées en les claquemurant dans la préciosité ou dans les marges d'une culture présentée comme étant plus officielle. 